(C) The Authors 2013

\title{
Sources, isolation, characterisation and evaluation of probiotics
}

\author{
Luis Fontana, Miriam Bermudez-Brito, Julio Plaza-Diaz, Sergio Muñoz-Quezada and Angel Gil* \\ Department of Biochemistry \& Molecular Biology II, School of Pharmacy and Institute of Nutrition \& Food Technology \\ "José Mataix", Biomedical Research Centre, University of Granada, Granada, Spain
}

\section{Abstract}

Probiotics are live microorganisms that, when ingested in adequate amounts, provide health benefits to the host. The strains most frequently used as probiotics include lactic acid bacteria and bifidobacteria, which are isolated from traditional fermented products and the gut, faeces and breast milk of human subjects. The identification of microorganisms is the first step in the selection of potential probiotics. The present techniques, including genetic fingerprinting, gene sequencing, oligonucleotide probes and specific primer selection, discriminate closely related bacteria with varying degrees of success. Additional molecular methods, such as denaturing gradient gel electrophoresis/temperature gradient gel electrophoresis and fluorescence in situ hybridisation, are employed to identify and characterise probiotics. The ability to examine fully sequenced genomes has accelerated the application of genetic approaches to elucidate the functional roles of probiotics. One of the best-demonstrated clinical benefits of probiotics is the prevention and treatment of acute and antibioticassociated diarrhoea; however, there is mounting evidence for a potential role for probiotics in the treatment of allergies and intestinal, liver and metabolic diseases. These positive effects are generally attributed to the ability of probiotics to regulate intestinal permeability, normalise host intestinal microbiota, improve gut immune barrier function and equilibrate the balance between pro-inflammatory and antiinflammatory cytokines. However, the positive effects of probiotics are not always substantiated by findings from properly conducted clinical trials. Notably, even when the results from randomised, placebo-controlled trials support the beneficial effects of a particular probiotic for a specific indication, the benefits are generally not translatable to other probiotic formulations.

Key words: Bifidobacteria: Lactic acid bacteria: Lactobacilli: Probiotics: Diseases

Currently, there is an increasing interest in and demand for probiotics, after a long history of safe use in fermented dairy products and an increased recognition of the beneficial effects of probiotics to human gut health ${ }^{(1)}$. According to the FAO of the $\mathrm{UN}$ and the $\mathrm{WHO}^{(2)}$, probiotics are live microorganisms which, when administered in adequate amounts, confer a health benefit on the host'. In particular, strains belonging to Bifidobacterium and Lactobacillus, the predominant and subdominant groups of the gastrointestinal microbiota, respectively $^{(3)}$, are the most widely used probiotic bacteria and are included in many functional foods and dietary supplements $^{(4-6)}$. The yeast Saccharomyces boulardii has also been shown to have health benefits ${ }^{(7)}$.

For probiotics to be successful, they must possess certain characteristics. The criteria for the selection of probiotics include tolerance to gastrointestinal conditions (gastric acid and bile), ability to adhere to the gastrointestinal mucosa and competitive exclusion of pathogens ${ }^{(8,9)}$. Traditionally, it has been proposed that a useful probiotic must fulfil the following criteria:
(1) Have a demonstrated beneficial effect on the host.

(2) Be non-pathogenic, non-toxic and free of significant adverse side effects.

(3) Be able to survive through the gastrointestinal tract (GIT; in vitro and in vivo).

(4) Be present in the product in an adequate number of viable cells to confer the health benefit.

(5) Be compatible with product matrix, processing and storage conditions to maintain the desired properties, and labelled accurately ${ }^{(10)}$.

The results of evidence-based analyses from human studies and animal models have shown the potential clinical effectiveness of probiotics on many diseases ${ }^{(11)}$. In fact, probiotics have been reported to suppress diarrhoea ${ }^{(12)}$, alleviate lactose intolerance $^{(13)}$ and post-operative complications ${ }^{(14)}$, exhibit antimicrobial $^{(15)}$ and anti-colorectal cancer activities ${ }^{(16,17)}$, reduce irritable bowel symptoms ${ }^{(18)}$ and prevent inflammatory bowel disease ${ }^{(19)}$. However, generalisations concerning the potential health benefits of probiotics should be not made

Abbreviations: AR, allergic rhinitis; IBS, irritable bowel syndrome; LAB, lactic acid bacteria; NEC, necrotising enterocolitis; RCT, randomised controlled trial; UTI, urinary tract infections.

*Corresponding author: Professor A. Gil, fax +34958 819132, email agil@ugr.es 
because probiotic effects tend to be strain specific; thus, the health benefit attributed to one strain is not necessarily applicable to another strain, even within one species ${ }^{(20)}$

The mechanisms underlying the beneficial effects of probiotics are largely unknown but are likely to be multi-factorial. However, several important mechanisms underlying the antagonistic effects of probiotics on various microorganisms include modification of the gut microbiota, competitive adherence to the mucosa and the epithelium, strengthening of the gut epithelial barrier and modulation of the immune system to convey an advantage to the host.

The aim of the present work was to review the sources, isolation methodology, characterisation and evaluation of probiotic strains. The various steps needed to characterise a bacterial strain as a novel probiotic are depicted in Fig. 1.

In the present study, we sought to conduct a literature review of the sources, isolation and characterisation and evaluation of probiotic strains. The present review summarises a total of 1500 works, published to the date from PubMed database (February 2012), and intends to provide an historical context and the state of this field. For this aim, the following search combinations were used: probiotics and sources; lactobacillus and isolation; bifidobacteria and isolation; probiotics and breast milk; probiotics and origin probiotics and fermented foods; isolation and characterisation and probiotics; probiotics and evaluation; and probiotics and randomised controlled trial (RCT).

\section{Sources}

Dairy and dairy-related products are a good source of probiotics $^{(1)}$. Within this context, lactic acid bacteria (LAB), bifidobacteria and other microorganisms obtained from fermented milks have been used for centuries. Spontaneous milk fermentation has a long history in different regions of Mongolia or Africa, and the use of beneficial microorganisms in fermented dairy products has been practised for many generations ${ }^{(21)}$.

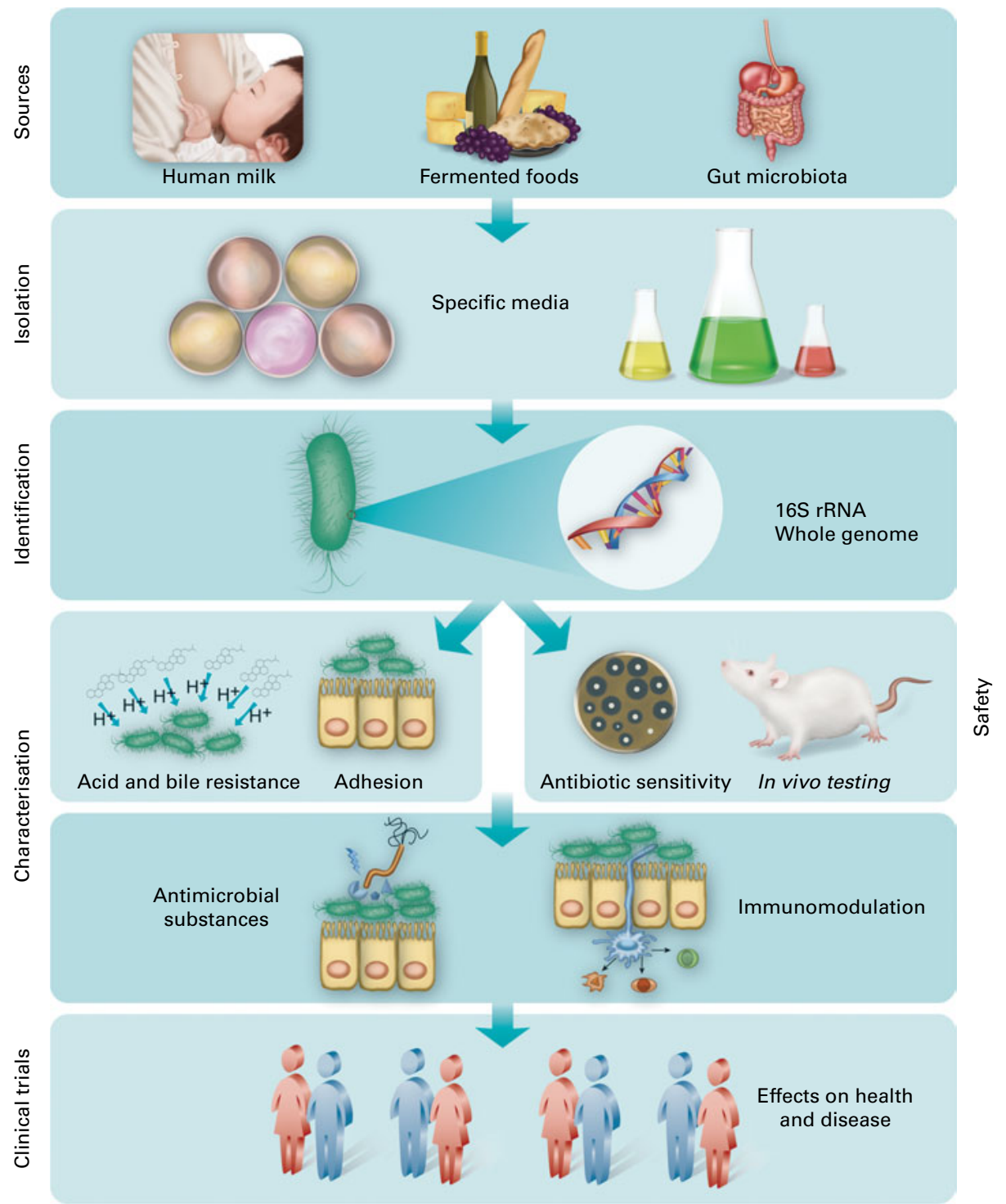

Fig. 1. Flow chart describing the various steps to be followed in order for a bacterial strain to qualify as a novel probiotic. rRNA, ribosomal RNA. 
These traditional fermented milks contain complex compositions of LAB species and therefore provide a useful source of probiotic strains. Thus, it is not surprising that in a recent work, 148 LAB strains were isolated from Kurut, a traditional naturally fermented yak milk from China in which L. delbrueckii subsp bulgaricus and Streptococcus thermophilus are the predominant microbial populations ${ }^{(22)}$. In addition, yeasts and lactobacillus strains with probiotic properties have been isolated from kefir grains, Masai milk and Koumiss, a fermented milk drink; these microorganisms are able to influence immune responses ${ }^{(23-26)}$.

Recent studies were conducted to evaluate traditional fermented products as potential natural sources of probiotic bacteria. Generally, most of the microorganisms isolated from fermented products belong to the Lactobacillus genus $^{(27-29)}$. Interestingly, in a recent work, a Weisella strain was isolated from Nigerian fermented foods and selected for its probiotic potential ${ }^{(30)}$.

Cheese is a dairy product with potential for the delivery of probiotic microorganisms into the human intestine. L. plantarum strains have been isolated from Italian, Argentinean and Bulgarian cheeses ${ }^{(31-33)}$.

Interestingly, it was observed that breast milk is not sterile, even when collected aseptically, which raises the possibility that breast milk harbours a natural bacterial inoculum ${ }^{(34)}$. The bacteria in breast milk have long been considered to be a consequence of skin or faecal contamination. Although the lactobacilli present in human milk are genotypically different from those isolated from the $\operatorname{skin}^{(35,36)}$, and the LAB strains present in breast milk were also observed in the faeces of the corresponding infants ${ }^{(37)}$, it has only recently become accepted that breast milk constitutes an interesting source of probiotic LAB and bifidobacteria for inclusion in infant formulas and foods targeted to both pre-term and full-term infants ${ }^{(38)}$. In addition, it has been reported that breast-fed infants have fewer allergies and gastrointestinal infections than formula-fed infants; therefore, the intestinal microbiota in the breast-fed infant might be considered to be ideally healthy ${ }^{(39)}$. Human breast milk comprises several predominant bacteria, such as staphylococci, streptococci, micrococci, lactobacilli, enterococci, lactococci and bifidobacteria ${ }^{(36,37,39-42)}$, and its intake favours the predominance of bifidobacteria and lactobacilli in the infant intestinal microbiota. Several authors have reported that lactobacilli isolated from breast milk are an efficient alternative to the use of commonly prescribed antibiotics for the treatment of infectious mastitis during lactation ${ }^{(43,44)}$. Moreover, it was reported that two Lactobacillus strains isolated from human breast milk enhanced natural and acquired immune responses through the activation of the natural killer and T-cell subsets and the expansion of regulatory $\mathrm{T}$ cells ${ }^{(42)}$.

Another source of probiotics is the human GIT. More than 500 different bacterial species reside in the adult human gut. In fact, many of the probiotic strains used today have been isolated from this source, such as L. gasseri and L. reuteri ${ }^{(45)}$. In addition, it has been reported that L. fermentum, isolated from human colonic mucosal biopsy samples, possesses antimicrobial activities against food-borne pathogens ${ }^{(46)}$. A common misconception is that probiotics must always colonise the intestinal tract to exert their effects. In fact, certain probiotics (e.g. B. longum and Bacteroides thetaiotaomicron) reside in the human intestinal microbiota, but others (e.g. $L$. case $i$ and $B$. animalis) do not ${ }^{(47)}$. Most of the probiotic strains, such as B. longum ${ }^{(48)}$ and L. acidophilus $\mathrm{RY}^{(49)}$, were isolated from the faecal samples of healthy adults and infants, respectively. Notably, in concordance with breast milk, several studies have reported the isolation of probiotics from breast-fed infant faeces ${ }^{(50,51)}$.

The isolation of probiotics is not limited to the human tract. The guts of several animal species, including pigs, rats and even poultry, are good sources of probiotics ${ }^{(52)}$. Recently, L. johnsonii CRL 1647, isolated from the Apis mellifera L. bee gut, was shown to exhibit a beneficial effect on honeybee colonies $^{(53)}$. Additionally, probiotic strains have been obtained from the intestinal tracts of marine and freshwater fish, such as Carassius auratus gibelio ${ }^{(54)}$, rainbow trout ${ }^{(55)}$ or shrimp ${ }^{(56)}$.

Other studies show that probiotic strains are also found in nondairy fermented substrates ${ }^{(57)}$. In vitro experiments have demonstrated that certain bacterial strains, isolated from meat (L. sakei, L. curvatus and Staphylococcus carnosus) and fruits (L.paracase $i$ and L. plantarum), can display functional and metabolic properties similar to those of human intestinal bacteria ${ }^{(58)}$. In addition, a recent work described the isolation of a Lactobacillus strain from brines of naturally fermented Aloreña green table olives ${ }^{(59)}$. Moreover, L. buchneri P2, isolated from pickled juice, demonstrated probiotic properties, such as cholesterol reduction, acid and bile tolerance and antimicrobial activity ${ }^{(60)}$

\section{Isolation, identification, characterisation and safety}

In microbial ecology, it is generally accepted that cultivation-based approaches provide an incomplete picture of microbial diversity. Ecological niches present a complex interrelation between the different species of microbes that cannot be mimicked using traditional culture methods. Molecular approaches that bypass the cultivation step have become popular as a means of identifying the microbial diversity of different sources. These methods have provided important information concerning microbial ecosystems, including the sources of probiotics. The first important step in studying an ecosystem is the isolation of its members. The identification of the microbes, especially in probiotic bacteria, is not valuable when we want to determine in vivo functions associated with beneficial effects on human health.

\section{Isolation}

The first step in the isolation of probiotic bacteria is to maintain the sample in adequate conditions before incubation in selective media. Most probiotics are anaerobic or facultatively anaerobic; therefore, the samples should be immediately placed under anaerobic conditions and processed as soon as possible (within $3 \mathrm{~h}$ ). The samples should be homogenised quickly and diluted and cultured in selective media (Sergio Muñoz-Quezada, Empar Chenoll, Jose Maria Vieites, Salvador Genoves, Jose Maldonado, Miriam Bermudez-Brito, Carolina Gomez-Llorente, Esther Matencio, Maria Jose Bernal, Fernando Romero, Antonio Suárez, Daniel Ramon, Angel Gil, unpublished results). 
Several media have been devised for the elective or selective isolation of bifidobacteria and lactobacilli ${ }^{(61-70)}$. Rogosa et $a l .{ }^{(68)}$ developed a selective medium for the isolation and enumeration of oral and faecal lactobacilli and Bifidobacterium that contains a Columbia agar base supplemented with propionic acid. The low $\mathrm{pH}$ of this medium, which is tolerated by lactobacilli and bifidobacteria, inhibits the growth of other predominating organisms in human faeces, such as Bacteroides and Eubacterium species.

The plates are incubated at $37^{\circ} \mathrm{C}$ for $48-72 \mathrm{~h}$ in an anaerobic atmosphere for the growth of bifidobacteria and other anaerobic species or in a $\mathrm{CO}_{2}$-rich atmosphere for the growth of lactobacilli. Subsequently, the colonies are isolated and transferred to broth or a new agar plate.

\section{Identification}

The identification of microbes in the GIT or food sources is the first step in the selection of potential probiotics. For many ecosystems, only a small percentage of microbes can be grown in culture $^{(71)}$. The taxonomic classification might be defined as the process of cataloguing biodiversity based on a polyphasic approach $^{(72)}$, which involves genotypic and phenotypic methods. Historically, phenotypic methods have been used to identify bacteria. The taxonomy for many decades heavily relied on the type of sugar fermentation and the fermentation products generated. Thus, the probiotics have been primarily classified as LAB. Today, 16S RNA gene analysis has become the method of choice. For the past two decades, microbiologists have used this conserved fragment for phylogenetic classification $^{(73,74)}$, and the relatedness among organisms is estimated through the comparison of their sequences in available databases (DDBJ, ENA, GenBank) ${ }^{(75-77)}$. The 16S RNA gene analysis has been combined with other methods to identify bacterial communities of the gut or ecological sources. The amplified 16S DNA can be coupled with PAGE using temperature (temperature gradient gel electrophoresis) or chemical denaturation (denaturing gradient gel electrophoresis) ${ }^{(78)}$, hybridised using fluorescent oligonucleotide probes that target specific $16 \mathrm{~S}$ (fluorescence in situ hybridisation) ${ }^{(79,80)}$ or digested with restriction enzymes (Terminal restriction fragment length polymorphism (T-RFLP)).

However, the 16S DNA fragment is extremely small (1500 bp) compared with the bacterial genome (30000$40000 \mathrm{bp})$. Complementary information is typically necessary due to insufficient base sequence diversity to differentiate strains of a given species. The $16 \mathrm{~S}$ to $23 \mathrm{~S}$ intergenic spacer region exhibits a great deal of sequence and length variation $^{(81)}$. The variation in this region has been used for differentiating species of prokaryotes. Undoubtedly, the analysis of the bacterial genome is the most useful tool to identify and characterise the processes underlying speciation and evolution in prokaryotes ${ }^{(82)}$. However, genome sequencing remains a laborious and relatively expensive technique.

\section{Characterisation}

The species of the genera Lactobacillus and Bifidobacterium are among the most important taxa of probiotics. When ingested, sufficient numbers of metabolically active bacteria must overcome the GIT barrier and transitorily persist in the GIT to exert their beneficial effects. This characteristic is important, although certain authors have shown beneficial effects of dead probiotics ${ }^{(83)}$. The capacity to tolerate an extremely low $\mathrm{pH}(1 \cdot 5-3 \cdot 0)$, gastric enzymes, bile salts and other intestinal enzymes, are the challenges for arriving alive in the $\mathrm{GIT}^{(84)}$. Various in vitro assays have been designed to mimic these stress conditions.

Resistance to low $\mathrm{pH}$ and biliary salts. Acid tolerance is one of the general criteria that is considered during the selection of potential probiotic strains to guarantee their viability and functionality ${ }^{(85)}$. In vitro systems, including controlled

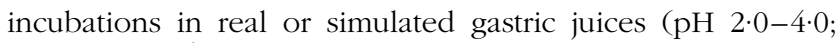
$70-180 \min ^{(86)}$ ), have been preferentially used in the evaluation of new probiotic strains. Complex models that simulate gastrointestinal transit have been developed ${ }^{(84,87)}$. Moreover, $1-4 \mathrm{~h}$ incubations in chemical and/or enzymatic media at a $\mathrm{pH}$ range of $1.5-3.0$ have also been performed.

The biliary salts facilitate the digestion of lipophilic compounds, but also behave as an antimicrobial agent by directly influencing the establishment of the intestinal microbiota. The relevant physiological concentrations of human bile range from 0.3 to $0.5 \%{ }^{(88,89)}$. In vitro assays are conducted in 0.3-0.7\% bovine bile (Oxgall) for 60-180 min. Probiotics show highly variable resistance to acid and bile salts, and this characteristic is both species and strain dependent. Several studies have reported that bifidobacteria are highly sensitive to low $\mathrm{pH}$ values. Certain species exhibit survival rates of $0 \%$ at $\mathrm{pH} 2.0$ for $90 \min ^{(86,90)}$, less than $1 \%$ at $\mathrm{pH} 3.0$ for $2 \mathrm{~h}^{(91)}$ or increased percentages at $\mathrm{pH} 3 \cdot 0-5 \cdot 0$ for $3 \mathrm{~h}^{(92)}$. The highest survival rates have been described for certain bifidobacteria ${ }^{(93-96)}$. Several Lactobacillus strains have shown a high resistance to low $\mathrm{pH}$. A study involving twenty Lactobacillus strains reported survival rates of $2-100 \%$ at $\mathrm{pH} 3.0$ for $1 \mathrm{~h}$. Certain bifidobacteria demonstrated a survival rate of $1-70 \%$ in $0.3 \%$ Oxgall for $90 \mathrm{~min}^{(87)}$. A total of two L. plantarum strains showed greater than $50 \%$ survival at $\mathrm{pH} 2 \cdot 0$ and $3 \cdot 0$ and $1.0 \%$ survival in $73-180 \%$ bile salt ${ }^{(97)}$.

Bacteria develop an adaptive response under moderate stress conditions, such as nutrient-rich or nutrient-poor media, $\mathrm{pH}$ and salt content ${ }^{(98)}$. Surprisingly, the modulation of protein complexes, transduction of signals or induction of genes ${ }^{(99)}$ might be used to modify food features ${ }^{(100)}$.

Adherence to intestinal epithelial cells. The adherence to intestinal epithelial cells and/or mucus is an important characteristic of probiotics to promote the gut residence time, pathogen exclusion and host and immune system interactions. Over the past 25 years, the Caco- 2 cell line has been used extensively to determine adhesion capacity ${ }^{(101)}$. Caco-2 cells form a homogeneous monolayer that resembles that of human mature enterocytes in the small intestine ${ }^{(102)}$; they also form crypts, which are typical structures of the epithelial monolayer $^{(103)}$. The colonic cell line HT-29 also displays typical characteristics of enterocyte differentiation and has been used for in vitro adhesion assays ${ }^{(104)}$. Adhesion to the intestinal mucosa is based on the immobilisation of mucin bound to the surface of microwell plates ${ }^{(105,106)}$ in several commercially 
available in vitro assays, whereas other useful in vitro models utilise cell lines developed to simulate a mucus-secreting environment (HT-29-MTX) ${ }^{(107,108)}$. The results of in vitro adhesion models, cell lines or their combination are highly variable $^{(109)}$. In fact, lactobacilli, bifidobacteria and pathogens show differences in adhesion to mucus, Caco-2, Caco-2 plus mucus, HT-29 MTX and Caco-2/HT29MTX. For L. rhamnosus GG, the reported capacities for adhesion in those systems are $10 \cdot 21,5 \cdot 17,3 \cdot 19,0.84$ and $0.85 \%$, respectively. Several in vitro studies have evaluated the adhesion of potential probiotic bacteria and their interactions with pathogens at the intestinal epithelial interface, and the results were dependent on the technique and strains used ${ }^{(105)}$.

Differences in the experimental conditions for assays of acid tolerance (medium acidified using $\mathrm{HCl}$ or lactic acid, with or without enzymes), bile resistance (bile origin and dose) and adhesion (mucus, cell lines, cells plus mucus) make it extremely difficult to compare their results. Remarkably, these characteristics are strain-specific traits that can be extremely variable within the species or genus. Therefore, the use of in vitro models is necessary to select the most promising strains. Thus, human clinical trials are the definitive tool to establish probiotic functionality.

Antimicrobial activity. When administered in adequate amounts, probiotics confer health benefits to the host ${ }^{(85)}$. An important beneficial effect is antimicrobial activity against pathogens ${ }^{(109)}$. Probiotics might act through a variety of mechanisms, including the production of antimicrobial substances, competition with pathogens for nutrients and adhesion sites and stimulation of the immune system ${ }^{(110)}$

Intestinal infections are mediated by the adhesion of pathogenic bacteria to mucosal surfaces and disruption of the intestinal microbiota. The probiotic bacteria might play protective roles through adhesion and colonisation of the mucosal surfaces, effectively competing with pathogens for binding sites and nutrients or/and immune stimulation ${ }^{(111,112)}$. Ferreira et $a l^{(113)}$ evaluated the ability of seven newly isolated strains of $L$. gasseri to adhere to intestinal mucosa and to autoaggregate and co-aggregate with the model pathogens Cronobacter sakazakii (ATCC 29544) and Clostridium difficile (ATCC 1296). All of the viable and non-viable bacterial strains used alone or in combination were able to auto-aggregate. The co-aggregation with $C$. sakazakii or $C$. difficile was higher $(P<0.05)$ in the non-viable bacterial strains.

The ability of probiotic strains to inhibit the growth of pathogens in broth and agar plates and to modulate the production of cytokines and growth factors in cell lines has been well documented using in vitro models in the evaluation of their biological effects. In addition, mice and other animal models are also useful to study the antimicrobial activity of probiotics. The antimicrobial effects of novel probiotics have been tested against Listeria monocytogenes and Helicobacter pylori in vitro, and against human rotavirus using in vivo infection models ${ }^{(94,95)}$. Several strains of lactobacilli and bifidobacteria successfully inhibited the growth of Escherichia coli ${ }^{(104,114-117)}$, Salmonella typhimurium, Shigella flexneri ${ }^{(118-120)}$ and C. difficile ${ }^{(121)}$. Moreover, an L. plantarum strain produced compounds with antifungal activity ${ }^{(122)}$.
Notably, in these studies, single strains were tested and the antimicrobial activities in most cases were due to the mixed host immune modulation and anti-infective activity of probiotics.

Although, in clinical studies, the use of probiotics is promising for the management of diarrhoea, H. pylori infection, atopic disease, necrotising enterocolitis (NEC) and inflammatory bowel diseases, there are uncertainties concerning the relative significance of probiotics, and the results from metaanalyses to determine the beneficial effects of probiotics ${ }^{(123)}$ are contradictory. Moreover, individual or mixtures of probiotic strains and the required dosages need to be determined, and additional clinical trials should be conducted to improve the available information.

\section{Safety}

Detailed reviews and opinions of present practices in the safety assessment of probiotics for human subjects have been published ${ }^{(124,125)}$. The European Food Safety Authority was established in 2002 to address the increasingly important and complex scientific and technical issues concerning food and feed safety in the European Union (regulation no. $178 / 2002$ ), but no formal safety testing guidelines for foodassociated microbes have been established. The Scientific Committee on Animal Nutrition proposed the 'qualified presumption of safety ${ }^{(126)}$ as an approach to safety evaluation, which involves four steps: (1) defining the taxonomy of the microbe; (2) collecting sufficient information providing the basis for qualified presumption of safety status, including scientific literature, history of use, industrial applications and ecological and human intervention data; (3) excluding pathogenicity and (4) defining the end use. If there are no safety concerns for a certain taxonomic group, or if any safety concerns have been allayed (qualification), then qualified presumption of safety status may be granted $^{(127)}$.

The LAB will be among the first groups to be evaluated. The introduction of this system appears to be favourably received and is considered to be more flexible than the Generally Recognised As Safe system used in the United States because it considers new emerging safety risks, such as the acquisition of antibiotic resistance and virulence determinants.

A variety of factors are considered in the assessment of the safety of probiotics, which include the following: (1) recording the isolation history and taxonomic classification of candidate probiotics, (2) manufacturing controls that eliminate contamination (including cross-contamination between batches) of probiotics with microbes or other substances, (3) assessing the association of probiotics with infectivity or toxicity at the strain level and (4) determining the physiological status of the consuming population, with special consideration for use in vulnerable populations, including newborn infants and the critically ill (dose administered and method of administration). When considering all of these factors, probiotics are generally considered to be 'safe', but this assumption cannot be made broadly, and such an assessment is specific to the many conditions indicated earlier. To market probiotics as 
foods or dietary supplements, the safety of each particular strain for the general population ${ }^{(128)}$ needs to be determined.

\section{Industrial production of probiotics}

The next step after a probiotic strain has been isolated, identified and characterised, and its safety has been approved, is scale-up production. Industrial production relies on two aspects. First, the microorganism needs to be cultured in adequate medium to allow growth in large quantities. Second, probiotic viability during manufacturing has to be secured. Both aspects are important, and scale-up production may become a bottleneck for an initially promising microorganism. Thus, certain strains might not grow properly, stand freeze- or spray-drying processes, or addition of preservatives to maintain viability throughout the shelf-life of the manufactured product.

\section{Evaluation of probiotics}

\section{Preclinical evaluation}

There is substantial evidence from in vitro and animal studies that known and potential probiotics exhibit strain-specific immunomodulatory effects.

In vitro studies. A large inventory of animal and human cell lines is available as models of the gut ${ }^{(129)}$, such as Caco-2, HT-29, IEC-6, IEC-18 and T84, to name a few. In most of the in vitro experimental models, the epithelial cells are cultivated as monolayers in which the establishment of a functional epithelial feature is not achieved.

To overcome this problem, researchers have attempted to reconcile the mechanisms underlying the complex and dynamic interactions between the intestinal epithelium and bacteria on the luminal side, and the epithelium and cells of the immune system on the basolateral side, using co-culture experiments with probiotics, dendritic cells, intestinal epithelial cells $^{(130)}$ and 3D models ${ }^{(129)}$. The 3D models are generated using an intestinal epithelial cell line of non-carcinogenic origin, which is cultured on a microporous membrane, enabling the polarisation of the cells. Below the microporous membrane (basolateral side), the epithelial cells are underlaid with immune cells (macrophages, dendritic cells), mimicking mucosal lymphoid tissue. Intestinal microbiota are added to the apical side of the membrane to study the effects of the microbiota. These three components (epithelia, immune cells and microbiota) are the most important factors in the gut; therefore, these models closely mimic the in vivo situation.

Animal studies. The immunomodulatory effects of probiotics have been demonstrated in experimental models of allergy, autoimmunity and inflammatory bowel disease ${ }^{(130)}$. Probiotic supplementation has exhibited protective effects during spontaneous and chemically induced colitis by downregulating the production of inflammatory cytokines or inducing regulatory mechanisms in a strain-specific manner. In animal models of allergen sensitisation and murine models of asthma and allergic rhinitis (AR), orally administered probiotics have demonstrated a strain-dependent decrease in IgE production by modulating systemic cytokine production. Certain probiotics have been shown to decrease airway hyperresponsiveness and inflammation through the induction of regulatory mechanisms.

\section{Clinical evaluation}

Many clinical studies have attempted to evaluate a great variety of probiotics under diverse physiological conditions and pathologies. However, many of these studies are flawed due to the small number of patients used or the lack of a control group. In fact, the European Food Safety Authority delivers scientific opinions on the substantiation of health claims related to probiotic strains. A high percentage of these claims is rejected by the European Food Safety Authority because a cause and effect relationship is not clearly established between the consumption of the probiotic and the beneficial effect it is supposed to have (mostly due to the small number, or even lack, of human intervention studies demonstrating such effects). The most reliable method of assessing the therapeutic benefits of any probiotic strain is the use of randomised, placebo-controlled trials, which are reviewed later and appear in Table 1.

Pregnancy and lactation. Asemi et al. ${ }^{(131)}$ assessed the effects of the daily consumption of probiotic yoghurt on inflammatory factors in pregnant women. The subjects consumed $200 \mathrm{~g}$ of probiotic yoghurt containing L. acidophilus La5 and B. animalis BB12 or $200 \mathrm{~g}$ of conventional yoghurt daily for 9 weeks. The consumption of the probiotic yoghurt significantly decreased the expression of C-reactive protein, but had no effect on $\mathrm{TNF}-\alpha$ in these subjects. In addition, the consumption of probiotic yoghurt among pregnant women resulted in increased levels of erythrocyte glutathione reductase but did not affect other indices of oxidative stress. ${ }^{(132)}$

Dugoua et al. ${ }^{(133)}$ reported that Lactobacillus and Bifidobacterium had no effect on the incidence of Caesarean section, birth weight or gestational age.

As mentioned in the 'Sources' section of the present review, lactobacilli isolated from breast milk are an efficient alternative to the use of commonly prescribed antibiotics for the treatment of infectious mastitis during lactation ${ }^{(43,44)}$

Allergy. Vliagoftis et al. ${ }^{(134)}$ evaluated the clinical evidence for the use of probiotics as a therapeutic modality for AR and asthma. The review included twelve RCT. A total of nine trials that evaluated clinical outcomes in AR showed an improvement due to the use of probiotics. All of the trials concerning perennial AR showed reduced symptom scoring and medication use with the administration of probiotics compared with the placebo. Moreover, in the five trials concerning seasonal AR, an improvement in the clinical outcomes was shown. The nine studies that reported various immunologic measurements of allergy showed no significant probiotic effects. The trials concerning the effect of probiotic administration on the treatment of asthma showed no positive effects. Taken together, these results suggest that probiotics might 
Table 1. Summary of selected human studies evaluating probiotic strains

\begin{tabular}{|c|c|c|}
\hline Study & Probiotics & Main outcomes \\
\hline \multicolumn{3}{|l|}{ Pregnancy and lactation } \\
\hline Asemi et al. ${ }^{(131)}$ & $\begin{array}{l}\text { Lactobacillus acidophilus La5 } \\
\text { Bifidobacterium animalis BB12 }\end{array}$ & $\downarrow$ C-reactive protein \\
\hline Asemi et al. ${ }^{(132)}$ & $\begin{array}{l}\text { L. acidophilus La5 } \\
\text { B. animalis BB12 }\end{array}$ & $\uparrow$ Erythrocyte glutathione levels \\
\hline Dugoua et al. ${ }^{(133)}$ & $\begin{array}{l}\text { Lactobacillus } \\
\text { Bifidobacterium }\end{array}$ & No effects on birth weight, gestational age or incidence of $\mathrm{C}$-section \\
\hline $\begin{array}{l}\text { Arroyo et al. }{ }^{(43)} \\
\text { Jiménez et al. }\end{array}$ & Lactobacilli from breast milk & $\downarrow$ Mastitis during lactation \\
\hline \multicolumn{3}{|l|}{ Allergy } \\
\hline Vliagoftis et al. ${ }^{(134)}$ & $\begin{array}{l}\text { B. longum } \\
\text { L. acidophilus } \\
\text { Bacillus clausii } \\
\text { L. paracasei } \\
\text { L. casei } \\
\text { L. rhamnosus }\end{array}$ & $\downarrow$ Symptom severity of allergic rhinitis and medication use \\
\hline
\end{tabular}

Kuitunen et al. ${ }^{(135)}$

Martínez-Cañavate et al. ${ }^{(136)}$

Boyle et al. ${ }^{(138)}$

Lee et al. ${ }^{(139)}$

Intestinal-related diseases

Olivares et al. ${ }^{(137)}$

Allen et al. ${ }^{(140)}$

Johnston et al. ${ }^{(141)}$

Bernaola Aponte et al. ${ }^{(142)}$

Alfaleh et al. ${ }^{(143)}$

Braga et al. ${ }^{(144)}$

Sang et al. ${ }^{(145)}$

Mimura et al. ${ }^{(146)}$

Kühbacher et al. ${ }^{(147)}$

Doherty et al. ${ }^{(148)}$
L. rhamnosus GG

L. rhamnosus LC705

B. breve $\mathrm{Bb} 99$

Propionibacterium freudenreichi ssp shermanii JS

L. gasseri CECT5714

L. coryniformis CECT5711

L. rhamnosus GG

L. rhamnosus $\mathrm{GG}$

L. gasseri CECT5714

L. coryniformis CECT5711

L. casei strain GG

Saccharomyces boulardii Enterococcus LAB SF68

Bacillus spp.

Bifidobacterium spp.

Lactobacillus spp.

Lactococcus spp.

Leuconostoc cremoris

Saccharomyces spp.

Streptococcus spp.

Lactobacilli

Bifidobacteria

Lactococci

Saccharomyces, etc

Mainly lactobacilli

L. casei

B. breve

B. bifidum

VSL\#3

VSL\#3

VSL\#3

Lactobacillus rhamnosus GG

L. johnsonii LA1 $\downarrow \mathrm{Hb}$ in infants

Negative correlation between $\mathrm{Hb}$ values at

6 months and faecal calprotectin at age 3 months

$\downarrow$ Plasma Ig E, $\uparrow$ mucosal Ig A

$\uparrow \mathrm{CD} 4+/ \mathrm{CD} 25+\mathrm{T}$ cells

$\uparrow$ Natural killer cells

No benefit in the treatment of eczema in children Risk of adverse effects

Effective in prevention but not treatment of pediatric atopic dermatitis

Improvement in intestinal habits

$\downarrow$ Duration and $\downarrow$ stool frequency in acute infectious diarrhoea

Protective effect in preventing antibiotic-associated diarrhoea

$\downarrow$ Duration and $\downarrow$ stool frequency in persistent diarrhoea

$\downarrow$ Incidence and mortality in necrotising enterocolitis

Benefit on the occurrence of necrotising enterocolitis Improvement in intestinal motility

$\uparrow$ Remission rate and $\downarrow$ recurrence rate of ulcerative colitis

Effective in maintaining antibiotic-induced remission in patients with pouchitis for 1 year

$\uparrow$ Total number of intestinal bacteria in pouchitis

$\uparrow$ Richness and diversity of the bacterial microbiota, especially the anaerobic microbiota

Repression in fungal microbiota

No effect 
Table 1. Continued

\begin{tabular}{|c|c|c|}
\hline Study & Probiotics & Main outcomes \\
\hline McFarland \& Dublin ${ }^{(149)}$ & Mainly lactobacilli and bifidobacteria & $\begin{array}{l}\text { Improvement in IBD symptoms } \\
\downarrow \text { Abdominal pain }\end{array}$ \\
\hline Gawrońska et al. ${ }^{(150)}$ & L. rhamnosus GG & $\downarrow$ Frequency but not the severity of pain in children with IBD \\
\hline Bausserman \& Michail ${ }^{(151)}$ & L. rhamnosus GG & $\downarrow$ Incidence of abdominal distention in children with IBD \\
\hline Enck et al. ${ }^{(152)}$ & $\begin{array}{l}\text { Enterococcus faecalis } \\
\text { Escherichia coli }\end{array}$ & $\downarrow$ Typical symptoms of IBD \\
\hline $\begin{array}{l}\text { Chronic liver disease } \\
\text { Liu et al. }{ }^{(153)}\end{array}$ & $\begin{array}{l}\text { Bacillus bifidus } \\
\text { L. acidophilus } \\
\text { L. bulgaricus } \\
\text { S. thermophilus }\end{array}$ & $\begin{array}{l}\downarrow \text { E. coli count, } \downarrow \text { intestinal flora imbalance } \\
\text { Improved symptoms and signs (debilitation, food intake, } \\
\text { appetite, abdominal distension and ascitic fluid) }\end{array}$ \\
\hline Aller et al. ${ }^{(154)}$ & $\begin{array}{l}\text { L. bulgaricus } \\
\text { S. thermophilus }\end{array}$ & Improved liver aminotransferases in NAFLD patients \\
\hline $\begin{array}{l}\text { Acute pancreatitis } \\
\text { Zhang et al. }^{(155)}\end{array}$ & $\begin{array}{l}\text { L. plantarum } 299 \\
\text { Pediococcus pentosaceus } \\
\text { Leuconostoc mesenteroides } \\
\text { L. paracasei } \\
\text { L. plantarum }\end{array}$ & $\downarrow$ Length of hospital stay \\
\hline Sharma et al. ${ }^{(156)}$ & $\begin{array}{l}\text { L. acidophilus } \\
\text { B. longus } \\
\text { B. bifidum } \\
\text { B. infantalis }\end{array}$ & No effects \\
\hline $\begin{array}{l}\text { Type } 2 \text { diabetes } \\
\text { Ejtahed et al. }{ }^{(157)}\end{array}$ & $\begin{array}{l}\text { L. acidophilus La5 } \\
\text { B. lactis } \mathrm{Bb} 12\end{array}$ & $\downarrow$ Total cholesterol, LDL-C and atherogenic indices \\
\hline $\begin{array}{l}\text { AIDS } \\
\text { Hummelen et al. }{ }^{(158)}\end{array}$ & $\begin{array}{l}\text { L. rhamnosus GR-1 } \\
\text { L. reuteri RC-14 }\end{array}$ & $\begin{array}{l}\text { No impact on the immune function of HIV-infected women } \\
\text { who were naïve to anti-retroviral treatment }\end{array}$ \\
\hline Trois et al. ${ }^{(159)}$ & $\begin{array}{l}\text { B. bifidum } \\
\text { S. thermophilus }\end{array}$ & Preservation of the immune function of HIV-infected children \\
\hline Anukam et al. ${ }^{(160)}$ & L. rhamnosus GR-1 & Preservation of the immune function of women naïve to anti-retrovirals \\
\hline $\begin{array}{l}\text { Urinary tract infections } \\
\text { Stapleton et al. }{ }^{(161)}\end{array}$ & L. crispatus & $\uparrow$ Vaginal colonisation, $\downarrow$ recurrent urinary tract infections \\
\hline $\begin{array}{l}\text { Respiratory infections } \\
\text { Hao et al. }{ }^{(162)}\end{array}$ & L. casei DN-114 001 & $\begin{array}{l}\downarrow \text { Episodes of acute upper respiratory infections } \\
\downarrow \text { Antibiotic use }\end{array}$ \\
\hline Siempos et al. ${ }^{(163)}$ & $\begin{array}{l}\text { Lactobacilli } \\
P . \text { pentosaceus } \\
\text { Leuconostoc mesenteroides }\end{array}$ & $\downarrow$ Incidence of ventilator-associated pneumonia \\
\hline $\begin{array}{l}\text { Spondyloarthritis } \\
\text { Jenks et al. }{ }^{(164)}\end{array}$ & $\begin{array}{l}\text { S. salivarius } \\
\text { B. lactis } \\
\text { L. acidophilus }\end{array}$ & No benefit over placebo \\
\hline
\end{tabular}

$\downarrow$, Decrease; $\uparrow$, increase; LAB, lactic acid bacteria; IBD, inflammatory bowel disease; NAFLD, non-alcoholic fatty liver disease.

have a beneficial effect in AR by reducing symptom severity and medication use.

In a study examining the effect of pre- and probiotics on the prevention of atopic disease, Kuitunen et al. ${ }^{(135)}$ conducted a randomised study of 1223 eligible mothers carrying a child with a high risk for allergy (at least one parent with doctordiagnosed asthma, AR or atopic eczema). Each subject received twice daily a probiotic combination of L. rhamnosus
GG, L. rhamnosus LC705, B. breve Bb99 and Propionibacterium freudenreichii ssp shermanii JS or placebo 4 weeks before delivery. Their infants received the same probiotics and $0.8 \mathrm{~g}$ of a galacto-oligosaccharide or placebo once daily from birth until 6 months of age. The children were observed until 2 years of age for the development of any allergic disease. Blood samples were obtained from ninety-eight infants at 6 months and 658 children at 2 years of age to measure 
the haematologic values. Faecal samples were collected at 3 and 6 months of age to measure immunologic development by the expression of calprotectin, $\alpha$-1-antitrypsin, TNF- $\alpha$ and IgA. At 6 months of age, the infants in the probiotic group had significantly lower $\mathrm{Hb}$ values than the placebo group. A significant negative correlation emerged between the $\mathrm{Hb}$ values at 6 months of age and the expression of faecal calprotectin at 3 months of age. The hematologic values in both groups were similar at 2 years of age.

Martínez-Cañavate et al. ${ }^{(136)}$ evaluated the immunological effects of two probiotic strains, L. gasseri CECT5714 and L. coryniformis CECT5711, in children suffering with allergies. Olivares et al. ${ }^{(137)}$ previously described a double-blinded, randomised, placebo-controlled comparative study with fortyfour allergic children, who were randomly distributed into two groups: a yoghurt group and a probiotic group. In the present study, intestinal and immunological parameters were measured in faecal and blood samples. The consumption of the probiotic product induced a significant decrease in the level of IgE in the plasma and an increase in CD $4+1$ $\mathrm{CD} 25+\mathrm{T}$ regulatory cells. The decrease in $\operatorname{IgE}$ was accompanied by a significant increase in mucosal IgA. Changes in other effector cells potentially involved in allergic reactions, such as eosinophiles, basophiles or other IgE + cells, were not detected. The consumption of the probiotic product also induced significant changes in the innate response, as a significant increase in natural killer cells was detected.

No evidence suggests that probiotics are an effective treatment for eczema in children; probiotic treatment carries a small risk of adverse events (infections and bowel ischaemia) and does not show any benefit in comparison with the placebo $^{(138)}$. A meta-analysis of six prevention and four treatment double-blind, randomised, placebo-controlled clinical trials in children with an age ranging from 0 to 13 years indicated that present evidence favours the use of probiotics for the prevention but not the treatment of paediatric atopic dermatitis ${ }^{(139)}$. There was a $61 \%$ risk reduction associated with the use of prenatal and/or postnatal probiotics for paediatric atopic dermatitis prevention. An additional analysis, which excluded the single study using a postnatal protocol, revealed a lower relative risk ratio. This result suggests that a prenatal component might be clinically important for maximising the prophylactic potential of probiotics. In terms of treatment, the summary effect size derived for both intergroup and intragroup differences failed to show any statistical significance.

\section{Intestinal-related diseases}

Intestinal function. Olivares et al. ${ }^{(137)}$ investigated the effect of a fermented product containing two probiotic strains, L. gasseri CECT5714 and L. coryniformis CECT5711, on several blood and faecal parameters related to intestinal function in the host. A total of thirty healthy volunteers were randomly distributed into two groups, one receiving a standard yoghurt and the other a similar dairy fermented product in which the L. delbreuckii subsp. bulgaricus yoghurt strain had been replaced by a combination of the probiotic strains $L$. gasseri CECT5714 and L. coryniformis CECT5711. The volunteers that received the probiotics reported no adverse effects, and the strains could be isolated from their faeces at a relatively high level. In fact, the concentration of faecal LAB significantly increased in the probiotic group. Additionally, the oral administration of the probiotics led to an improvement in several parameters, such as the production of SCFA, faecal moisture and frequency and volume of the stools. As a result, the volunteers assigned to the probiotic group perceived a clear improvement in their intestinal habits ${ }^{(137)}$.

Infectious diarrboea. A Cochrane review on the efficacy of probiotics for treating infectious diarrhoea, including both adults and children, evaluated sixty-three studies with a total of 8014 participants. No adverse events were attributed to probiotic intervention. The use of probiotics reduced the duration of diarrhoea, although the size of the effect varied considerably between studies. The average of the effect was significant for the mean duration of diarrhoea (lasting $\geq 4 \mathrm{~d}$ ) and stool frequency on day 2 . The authors concluded that, when used alongside rehydration therapy, probiotics appear to be safe and have clear beneficial effects in shortening the duration and reducing stool frequency in acute infectious diarrhoea ${ }^{(140)}$.

Antibiotic-associated diarrboea. A 2011 Cochrane review meta-analysis evaluated the results of sixteen randomised, parallel, placebo-controlled trials that investigated antibioticassociated diarrhoea in children ( $0-18$ years of age) receiving antibiotics $^{(141)}$. Treatment with probiotics was compared with treatment with placebo, active alternative prophylaxis or no treatment, and the incidence of diarrhoea secondary to antibiotic use was measured. The trials included treatment with Bacillus spp., Bifidobacterium spp., Lactobacillus spp., Lactococcus spp., Leuconostoc cremoris, Saccharomyces spp. or Streptococcus spp., individually or in combination. Despite the heterogeneity in probiotic strain, dose and duration, and the quality of the study, the overall evidence suggests a protective effect of probiotics in preventing antibiotic-associated diarrhoea.

Persistent diarrboea. The evidence suggesting that probiotics might be effective in treating persistent diarrhoea in children is scarce. Bernaola Aponte et al. ${ }^{(142)}$ reviewed RCT comparing a specified probiotic agent with placebo or no probiotic in children with persistent diarrhoea. In all, four trials, with a total of 464 participants, were included in this metaanalysis. Treatment with probiotics reduced the duration of persistent diarrhoea in two trials. Similarly, the stool frequency was reduced with the use of probiotics in two trials. One trial reported a shorter hospital stay, which was significant, but the numbers were small. No adverse events were reported.

Necrotising enterocolitis. Alfaleh et al. ${ }^{(143)}$ performed a meta-analysis with sixteen randomised or quasi-RCT that involved 2842 preterm infants of $<37$ weeks gestational age and/or weighing $<2500 \mathrm{~g}$ at birth. These trials were highly variable with regard to enrolment criteria (i.e. birth weight and gestational age), baseline risk of NEC in the control groups, timing, dosing, probiotics formulations and feeding regimens. The data regarding extremely low birth weight infants could not be extrapolated. Enteral probiotic supplementation significantly reduced the incidence of severe NEC (stage II or more) and mortality. There was no evidence 
of a significant reduction of nosocomial sepsis. Moreover, there was no evidence of systemic infection with the use of probiotics in these trials. The authors concluded that enteral supplementation with probiotics prevents severe NEC, although more studies are needed to assess the efficacy of probiotic use in extremely low birth weight infants and assess the most effective formulation and dose to be utilised.

Braga et $a l .{ }^{(144)}$ evaluated the effect of a combined supplementation of $L$. casei and B. breve in preterm infants with low birth weight on the occurrence of NEC as a primary outcome. The use of probiotics had a beneficial effect on the occurrence of NEC at stage $\geq 2$ using Bell's criteria and was associated with an improvement in intestinal motility based on the time required to reach full enteral feeding.

Ulcerative colitis. Probiotic treatment is effective in maintaining remission in ulcerative colitis ${ }^{(145)}$. A total of thirteen RCT were reviewed. Compared with the non-probiotics group, the remission rate for ulcerative colitis patients who received probiotics was 1.35 (95\% CI 0.98, 1.85). Compared with the placebo group, the remission rate of ulcerative colitis patients that received probiotics was $2 \cdot 00$ (95\% CI 1.35, 2.96). During the course of treatment, patients who received probiotics for less than 12 months showed a remission rate of 1.36 (95\% CI 1.07, 1.73) compared with the group treated with non-probiotics. Compared with the non-probiotics group, the recurrence rate of ulcerative colitis in patients that received probiotics was $0.69(95 \%$ CI 1.01, 2.47). The recurrence rate was 0.25 (95\% CI $0 \cdot 12,0.51)$ in the mild-to-moderate group that received probiotics compared with the group that did not receive probiotics. The group that received $B$. bifidum treatment had a recurrence rate of 0.25 (95\% CI $0.12,0.50)$ compared with the non-probiotics group.

Pouchitis is a major complication after ileal pouch anal anastomosis in patients with ulcerative colitis. Mimura et al. ${ }^{(146)}$ showed that a single daily high dose $(6 \mathrm{~g})$ of probiotic VSL\#3 was effective in maintaining antibiotic-induced remission in patients with pouchitis for 1 year. The remission was maintained for 1 year in $85 \%$ of patients in the VSL\#3 group compared with $6 \%$ of patients in the placebo group. In a more recent paper, patients with pouchitis in remission that had been induced by antibiotic therapy were recruited to receive either the VSL\#3 probiotic compound or placebo for the maintenance of remission ${ }^{(147)}$. Biopsies were obtained before and 2 months after the initiation of VSL $\# 3$ or placebo treatment. Therapy with VSL\#3 increased the total number of intestinal bacterial cells and the richness and diversity of the bacterial microbiota, especially the anaerobic microbiota, whereas the fungal flora was repressed. In contrast, patients who relapsed while receiving placebo showed a reduced diversity of the mucosal microbiota.

Crobn's disease. Doherty et al. ${ }^{(148)}$ recently reviewed trials comparing antibiotics or probiotics with placebo in the prevention of endoscopic or clinical recurrence of Crohn's disease following surgical resection. A total of seven studies were identified as suitable for inclusion (two comparing antibiotics with the placebo and five comparing probiotics with the placebo). Probiotic administration was not associated with any significant difference in the risk of recurrence compared with the placebo.

Irritable bowel syndrome. Irritable bowel syndrome (IBS) is a chronic condition affecting 3-25\% of the population for which no curative treatment is available. Accordingly, therapy is aimed at reducing symptoms. Because an alteration of the normal intestinal microbiota has been observed in IBS, probiotics were considered to be useful in reducing symptoms. McFarland \& Dublin ${ }^{(149)}$ reviewed twenty trials that included a total of 1404 subjects. Probiotic use was associated with improvements in global IBS symptoms compared with the placebo. Probiotics were also associated with less abdominal pain.

Gawrońska et al. ${ }^{(150)}$ investigated the efficacy of L. rhamnosus GG for treating functional dyspepsia, IBS or functional abdominal pain in children. These authors found that L. rhamnosus GG reduced the frequency but not the severity of pain in children with IBS.

In contrast to these findings, the administration of L. rhamnosus GG to fifty children (6-20 years) with IBS for 6 weeks was not superior to the placebo in relieving abdominal pain. There was no difference in the other gastrointestinal symptoms, except for a lower incidence of perceived abdominal distension ${ }^{(151)}$.

Treatment of IBS with the bacterial lysate of Enterococcus faecalis and E. coli was effective and superior to the placebo in reducing the typical symptoms of IBS in patients treated by general practitioners ${ }^{(152)}$. In all, 297 patients with IBS were treated for 8 weeks with this bacterial lysate or a placebo, in a double-blinded, randomised fashion. The responders had at least a $50 \%$ decrease in the global symptom score, and the abdominal pain score was $\geq 1$ visit during treatment. The responder rate in global symptom score to the probiotics was $102 / 149(68.5 \%)$ compared with the placebo rate of $56 / 148(37.8 \% ; P<0.001)$, the improvement in abdominal pain score was 108/149 (72.5\%) and 66/148 (44.6\%), respectively $(P=0.001)$. The number-needed-to-treat was $3 \cdot 27$ for global symptom score and 3.59 for abdominal pain score. The Kaplan-Meier analysis revealed an average response time of 4-5 weeks for active treatment and more than 8 weeks for treatment with the placebo $(P<0.0001)$.

Chronic liver disease. Patients with chronic liver disease generally have an intestinal microbiota imbalance that is related to the development and worsening of the disease. Liu et $a l .{ }^{(153)}$ conducted a randomised, placebo-controlled trial, pre-test/post-test controlled group design. Patients were randomised to an experimental group (forty-one patients) or a control group (forty patients). Patients in the experimental group were given probiotic yoghurt containing Bacillus bifidus, L. acidophilus, L. bulgaricus and S. thermophilus. The subjects in the control group had meals only and were not provided with the probiotic yoghurt. After intervention, the experimental group had a lower E. coli count and a reduced intestinal microbiota imbalance. A comparison of the experimental and control groups after the intervention showed that the former had improved symptoms and signs, including a significant improvement in debilitation, food intake, appetite, abdominal distension and ascitic fluid. 
Aller et al. ${ }^{(154)}$ showed that the ingestion of a tablet of 500 million L. bulgaricus and $S$. thermophilus improved liver aminotransferase levels in patients with non-alcoholic fatty liver disease.

Acute pancreatitis. Zhang et al. ${ }^{(155)}$ reviewed all relevant RCT that studied the effects of pre-, pro- or synbiotics in patients with acute pancreatitis. A total of seven randomised studies with 559 patients were included. Pre-, pro- or synbiotic treatment showed no influence on the incidence of postoperative infections, pancreatic infection, multiple organ failure and systemic inflammatory response syndrome. There were also no significant differences in the length of antibiotic therapy and mortality. However, pre-, pro- or synbiotic treatment was associated with a reduced length of hospital stay.

Sharma et al. ${ }^{(156)}$ investigated the role of probiotics on gut permeability and endotoxaemia in patients with acute pancreatitis. Patients were randomised to receive either a placebo or a mixture of L. acidophilus, B. longus, B. bifidum, $B$. infantalis and $25 \mathrm{mg}$ of fructo-oligosaccharide. No significant trend was identified concerning the effect of probiotics on gut permeability or endotoxaemia in acute pancreatitis. However, the study was underpowered owing to premature study termination.

Type 2 diabetes. Ejtahed et al. ${ }^{(157)}$ investigated the administration of probiotics in type 2 diabetic patients, who were randomised to receive either $300 \mathrm{~g}$ of probiotic yoghurt containing L. acidophilus La5 and B. lactis Bb12 or $300 \mathrm{~g}$ of conventional yoghurt for 6 weeks. Probiotic consumption caused significant decreases in total cholesterol, LDL-C and the atherogenic indices total cholesterol:HDL-C ratio and LDL-C:HDL-C ratio compared with the controls.

AIDS. HIV-infected women who were naïve to antiretroviral treatment were randomised to receive oral capsules containing L. rhamnosus GR-1 and L. reuteri $\mathrm{RC}-14$ or placebo twice daily for 25 weeks. The CD 4 count and immune markers (IgG, IgE, IFN $\gamma$ and IL-10) were measured at baseline and during follow-up. Probiotics had no impact on the immune function in the present study ${ }^{(158)}$.

Other trials have shown a preservation of the immune function with the use of probiotics among non-responsive children or those treated with the anti-retrovirals B. bifidum and S. termophilus in Brazil ${ }^{(159)}$ and among women naïve to anti-retrovirals who were treated with L. rhamnosus GR-1 in Nigeria $^{(160)}$.

Urinary tract infections. Urinary tract infections (UTI) are common among women and frequently recur. The depletion of vaginal lactobacilli is associated with UTI risk, which suggests that repletion might be beneficial. Stapleton et $a{ }^{(161)}$ conducted a double-blind placebo-controlled trial of a L. crispatus intravaginal suppository probiotic for the prevention of recurrent UTI in premenopausal women. Recurrent UTI occurred in $15 \%$ of women receiving probiotics compared with $27 \%$ of women receiving placebo (relative risk, $0.5 ; 95 \%$ CI $0 \cdot 2,1 \cdot 2)$. High-level vaginal colonisation with L. crispatus throughout follow-up was associated with a significant reduction in recurrent UTI only in the group that received probiotics.
Respiratory infections. Hao et al. ${ }^{(162)}$ performed a meta-analysis that included ten RCT comparing probiotics with placebo to prevent acute upper respiratory tract infections. Probiotics were more effective than the placebo in reducing the number of participants experiencing episodes of acute upper respiratory tract infections, the rate ratio of episodes of acute upper respiratory tract infections and reducing antibiotic use.

A meta-analysis of five RCT showed that the administration of probiotics is associated with lower incidence of ventilatorassociated pneumonia compared with the placebo ${ }^{(163)}$.

Spondyloarthritis. Jenks et al. ${ }^{(164)}$ studied the effect of an orally administered probiotic on disease activity, fatigue, quality of life and intestinal symptoms in patients with active spondyloarthritis. In the present randomised placebo-controlled trial, the probiotic combination did not demonstrate significant benefit over the placebo.

\section{Conclusions and future directions}

Lactobacilli and bifidobacteria are the genera most frequently used as probiotics. Traditional fermented products and the breast milk, GIT and faeces of human subjects are the primary sources of these microorganisms. Probiotics are isolated by culture in selective media. Currently, the identification of probiotic strains is facilitated by the sequencing of their $16 S \mathrm{RNA}$ genes. Prior to their evaluation, probiotics must be characterised using the following criteria: (1) the capacity to resist extremely low $\mathrm{pH}$, gastric and intestinal enzymes and bile salts, (2) the capacity to adhere to intestinal epithelial cells, (3) antimicrobial activity and (4) safety. The evaluation of probiotics can be conducted at the preclinical (cell and animal models) and clinical levels. Among the latter, the most reliable studies to assess the therapeutic benefits of any probiotic strain are randomised, placebo-controlled trials.

Probiotics have been shown to promote a variety of biological effects in a number of physiological conditions and pathologies, including allergy, intestinal and liver diseases, urinary and upper respiratory infections, AIDS and metabolic diseases. These effects are strain specific and are primarily mediated through changes in the faecal microbiota and immune modulation. RCT concerning the appropriate clinical evaluation of probiotics, with an adequate and statistically sufficient number of subjects related to the main outcome variables, should be performed in a variety of diseases. In addition, multi-centre and replicate studies are necessary to evaluate the actual role of probiotics in the amelioration of symptoms for many diseases. The number of studies concerning the mechanism of probiotics in cell and animal models is scarce. Apparently, many probiotics are able to modulate both the innate and adaptive immune responses; however, the molecular basis of these effects remains unknown.

\section{Acknowledgements}

The authors declare that they have no conflict of interest. Part of the research currently in progress in our laboratory is funded by the company Hero España, S. A. through the 
grants no. 3143 and 3545 managed by the Fundación General Empresa-Universidad de Granada. The author contributions are as follows: M. B.-B. wrote the abstract, the introduction and the section 'Sources'. J. P.-D. and S. M.-Q. wrote the section 'Isolation, identification, characterisation and safety' and made Fig. 1. L. F. and A. G. wrote the section 'Evaluation' and Table 1.

\section{References}

1. Liong MT (editor) (2011) Probiotics: biology, genetics and health aspects. Berlin: Springer-Verlag.

2. FAO/WHO (2001) Health and nutritional properties of probiotics in food including powder milk with live lactic acid bacteria. http://www.who.int/foodsafety/publications/ fs_management/en/probiotics.pdf

3. Guarner F \& Malagelada JR (2003) Gut flora in health and disease. Lancet 361, 512-519.

4. Gourbeyre P, Denery S \& Bodinier M (2011) Probiotics, prebiotics, and synbiotics: impact on the gut immune system and allergic reactions. J Leukoc Biol 89, 685-695.

5. Macpherson AJ \& Harris NL (2004) Interactions between comensal intestinal bacteria and the immune system. Nat Rev Immunol 4, 478-485.

6. Frick JS, Schenk K, Quitadamo M, et al. (2007) Lactobacillus fermentum attenuates the proinflammatory effect of Yersinia enterocolitica on human epithelial cells. Inflamm Bowel Dis 13, 83-90.

7. McFarland (2006) Meta-analysis of probiotics for the prevention of antibiotic associated diarrhea and the treatment of Clostridium difficile disease. Am J Gastroenterol 101, 812-822.

8. Collins JK, Thornton G \& Sullivan GO (1998) Selection of probiotic strains for human application. Int Dairy $J \mathbf{8}$, 487-490.

9. Ouwehand AC, Salminen S \& Isolauri E (2002) Probiotics: an overview of beneficial effects. Antonie van Leeuwenhoek 82, 279-289.

10. Collado MC, Gueimonde M \& Salminen S (2010) Probiotics in adhesion of pathogens: mechanisms of action. Bioactive Foods Promot Health 23, 353-370.

11. Yan F \& Polk DB (2011) Probiotics and immune health. Curr Opin Gastroenterol 27, 496-501.

12. Lye HS, Kuan CY, Ewe JA, et al. (2009) The improvement of hypertension by probiotics: effects on cholesterol, diabetes, renin, and phytoestrogens. Int J Mol Sci 10, 3755-3775.

13. Pelletier X, Laure-Boussuge S \& Donazzolo Y (2001) Hydrogen excretion upon ingestion of dairy products in lactoseintolerant male subjects: importance of the live flora. Eur J Clin Nutr 55, 509-512.

14. Woodard GA, Encarnacion B, Downey JR, et al. (2009) Probiotics improve outcomes after Roux-en-Y gastric bypass surgery: a prospective randomized trial. J Gastrointest Surg 13, 1198-1204.

15. Karska-Wysocki B, Bazo M \& Smoragiewicz W (2010) Antibacterial activity of Lactobacillus acidophilus and Lactobacillus casei against methicillin-resistant Staphylococcus aureus (MRSA). Microbiol Res 165, 674-686.

16. Liong MT (2008) Safety of probiotics: translocation and infection. Nutr Rev 66, 192-202.

17. Rafter J, Bennett M, Caderni G, et al. (2007) Dietary synbiotics reduce cancer risk factors in polypectomized and colon cancer patients. Am J Clin Nutr 85, 488-496.
18. Moayyedi P, Ford AC, Talley NJ, et al. (2010) The efficacy of probiotics in the treatment of irritable bowel syndrome: a systematic review. Gut 59, 325-332.

19. Golowczyc MA, Mobili P, Garrote GL, et al. (2007) Protective action of Lactobacillus kefir carrying S-layer protein against Salmonella enterica serovar enteritidis. Int J Food Microbiol 118, 264-273.

20. Williams NT (2010) Probiotics. Am J Health Syst Pharm 67 , 449-458.

21. Yu J, Wang WH, Menghe BL, et al. (2011) Diversity of lactic acid bacteria associated with traditional fermented dairy products in Mongolia. J Dairy Sci 94, 3229-3241.

22. Sun Z, Liu W, Gao W, et al. (2010) Identification and characterization of the dominant lactic acid bacteria from kurut: the naturally fermented yak milk in Qinghai, China. J Gen Appl Microbiol 56, 1-10.

23. Lopitz-Otsoa F, Rementeria A, Elguezabal N, et al. (2006) Kefir: a symbiotic yeasts-bacteria community with alleged healthy capabilities. Rev Iberoam Micol 23, 67-74.

24. Romanin D, Serradell M, González Maciel D, et al. (2010) Down-regulation of intestinal epithelial innate response by probiotic yeasts isolated from kefir. Int J Food Microbiol 140, 102-108.

25. Patrignani F, Lanciotti R, Mathara JM, et al. (2006) Potential of functional strains, isolated from traditional Maasai milk, as starters for the production of fermented milks. Int $J$ Food Microbiol 107, 1-11.

26. Ya T, Zhang Q, Chu F, et al. (2008) Immunological evaluation of Lactobacillus casei Zhang: a newly isolated strain from koumiss in Inner Mongolia, China. BMC Immunol 9, 68 .

27. Vizoso Pinto MG, Franz CM, Schillinger U, et al. (2006) Lactobacillus spp. with in vitro probiotic properties from human faeces and traditional fermented products. Int $J$ Food Microbiol 109, 205-214.

28. Lim SM \& Im DS (2009) Screening and characterization of probiotic lactic acid bacteria isolated from Korean fermented foods. J Microbiol Biotechnol 19, 178-186.

29. Won TJ, Kim B, Lim YT, et al. (2011) Oral administration of Lactobacillus strains from Kimchi inhibits atopic dermatitis in NC/Nga mice. J Appl Microbiol 110, 1195-1202.

30. Ayeni FA, Sánchez B, Adeniyi BA, et al. (2011) Evaluation of the functional potential of Weissella and Lactobacillus isolates obtained from Nigerian traditional fermented foods and cow's intestine. Int J Food Microbiol 147, 97-104.

31. Zago M, Fornasari ME, Carminati D, et al. (2011) Characterization and probiotic potential of Lactobacillus plantarum strains isolated from cheeses. Food Microbiol 28, 1033-1040.

32. Ugarte MB, Guglielmotti D, Giraffa G, et al. (2006) Nonstarter lactobacilli isolated from soft and semihard Argentinean cheeses: genetic characterization and resistance to biological barriers. J Food Prot 69, 2983-2991.

33. Georgieva RN, Iliev IN, Chipeva VA, et al. (2008) Identification and in vitro characterization of Lactobacillus plantarum strains from artisanal Bulgarian white brined cheeses. J Basic Microbiol 48, 234-244.

34. West PA, Hewitt JH \& Murphy OM (1979) Influence of methods of collection and storage on the bacteriology of human milk. J Appl Bacteriol 46, 269-277.

35. Martin R, Jiménez E, Heilig H, et al. (2009) Isolation of bifidobacteria from breast milk and assessment of the bifidobacterial population by PCR-denaturing gradient gel electrophoresis and quantitative real-time PCR. Appl Environ Microbiol 75, 965-969. 
36. O'hara AM \& Shanahan F (2006) The gut flora as a forgotten organ. EMBO Rep 7, 688-693.

37. Martin R, Langa S, Reviriego C, et al. (2003) Human milk is a source of lactic acid bacteria for the infant gut. J Pediatr 143, 754-758.

38. Arboleya S, Binetti A, Salazar N, et al. (2012) Establishment and development of intestinal microbiota in preterm neonates. FEMS Microbiol Ecol 79, 763-772.

39. Solis G, Reyes-Gavilan CG, De los Fernandez N, et al. (2010) Establishment and development of lactic acid bacteria and bifidobacteria microbiota in breastmilk and the infant gut. Anaerobe 16, 307-310.

40. Gueimonde M, Laitinen K, Salminen S, et al. (2007) Breast milk: a source of bifidobacteria for infant gut development and maturation. Neonatology 92, 64-66.

41. Martin R, Langa S, Reviriego C, et al. (2004) The commensal microflora of human milk: new perspectives for food bacterio therapy and probiotics. Trends Food Sci Technol 15, 121-127.

42. Perez-Cano FJ, Dong K \& Yaqoob P (2010) In vitro immunomodulatory activity of Lactobacillus fermentum CECT5716 and Lactobacillus salivarius CECT5713: two probiotic strains isolated from human breast milk. Immunobiology 215, 996-1004.

43. Arroyo R, Martín V, Maldonado A, et al. (2010) Treatment of infectious mastitis during lactation: antibiotics versus oral administration of lactobacilli isolated from breast milk. Clin Infect Dis 15, 1551-1558.

44. Jiménez E, Fernández L, Maldonado A, et al. (2008) Oral administration of Lactobacillus strains isolated from breast milk as an alternative for the treatment of infectious mastitis during lactation. Appl Environ Microbiol 74, 4650-4655.

45. Ryan KA, Jayaraman T, Daly P, et al. (2008) Isolation of lactobacilli with probiotic properties from the human stomach. Lett Appl Microbiol 47, 269-274.

46. Varma P, Dinesh KR, Menon KK, et al. (2010) Lactobacillus fermentum isolated from human colonic mucosal biopsy inhibits the growth and adhesion of enteric and foodborne pathogens. J Food Sci 75, M546-M551.

47. Ohland CL \& Macnaughton WK (2010) Probiotic bacteria and intestinal epithelial barrier function. Am J Physiol Gastrointest Liver Physiol 298, G807-G819.

48. Srůtková D, Spanova A, Spano M, et al. (2011) Efficiency of PCR-based methods in discriminating Bifidobacterium longum ssp. longum and Bifidobacterium longum ssp. infantis strains of human origin. J Microbiol Methods 87, $10-16$.

49. Lin PP, Hsieh YM \& Tsai CC (2009) Antagonistic activity of Lactobacillus acidophilus RY2 isolated from healthy infancy feces on the growth and adhesion characteristics of enteroaggregative Escherichia coli. Anaerobe 15, 122-126.

50. Martín R, Jiménez E, Olivares M, et al. (2006) Lactobacillus salivarius CECT 5713, a potential probiotic strain isolated from infant feces and breast milk of a mother-child pair. Int J Food Microbiol 112, 35-43.

51. Acharya MR \& Shah RK (2002) Selection of human isolates of bifidobacteria for their use as probiotics. Appl Biochem Biotechnol 102-103, 81-98.

52. Petrof EO (2009) Probiotics and gastrointestinal disease: clinical evidence and basic science. Antiinflamm Antiallergy Agents Med Chem 8, 260-269.

53. Audisio MC \& Benítez-Ahrendts MR (2011) Lactobacillus johnsonii CRL1647, isolated from Apis mellifera L. bee-gut, exhibited a beneficial effect on honeybee colonies. Benef Microbes 2, 29-34.
54. Chu W, Lu F, Zhu W, et al. (2011) Isolation and characterization of new potential probiotic bacteria based on quorumsensing system. J Appl Microbiol 110, 202-208.

55. Pérez-Sánchez T, Balcázar JL, García Y, et al. (2011) Identification and characterization of lactic acid bacteria isolated from rainbow trout, Oncorbynchus mykiss (Walbaum), with inhibitory activity against Lactococcus garvieae. J Fish Dis 34, 499-507.

56. Hill JE, Baiano JC \& Barnes AC (2009) Isolation of a novel strain of Bacillus pumilus from penaeid shrimp that is inhibitory against marine pathogens. J Fish Dis 32, 1007-1016.

57. Rivera-Espinoza Y \& Gallardo-Navarro Y (2010) Non-dairy probiotic products. Food Microbiol 27, 1-11.

58. Haller D, Colbus H, Ganzle MG, et al. (2001) Metabolic and functional properties of lactic acid bacteria in the gastrointestinal ecosystem: a comparative in vitro study between bacteria of intestinal and fermented food origin. Syst Appl Microbiol 24, 218-226.

59. Abriouel H, Benomar N, Pulido RP, et al. (2011) Annotated genome sequence of Lactobacillus pentosus MP-10, which has probiotic potential, from naturally fermented Aloreña green table olives. J Bacteriol 193, 4559-4560.

60. Zeng XQ, Pan DD \& Guo YX (2010) The probiotic properties of Lactobacillus buchneri P2. J Appl Microbiol 108, 2059-2066.

61. Hartemink R \& Rombouts FM (1999) Comparison of media for the detection of bifidobacteria, lactobacilli and total anaerobes from faecal samples. J Microbiol Meth 36, $181-192$.

62. Hartemink R, Kok BJ, Weenk GH, et al. (1996) RaffinoseBifidobacterium (RB) agar, a new selective medium for bifidobacteria. J Microbiol Meth 27, 33-43.

63. Beerens H (1990) An elective and selective isolation medium for Bifidobacterium spp. Lett Appl Microbiol 11, $155-157$.

64. Dave RI \& Shah NP (1995) Evaluation of media for selective enumeration of Streptococcus thermophilus, Lactobacillus delbrueckii ssp. bulgaricus, Lactobacillus acidophilus, and bifidobacteria. J Dairy Sci 79, 1529-1536.

65. Munoa FJ \& Pares R (1988) Selective medium for isolation and enumeration of Bifidobacterium species. Appl Environ Microbiol 54, 1715-1718.

66. Nebra Y \& Blanch AR (1999) A new selective medium for Bifidobacterium spp. Appl Environ Microbiol 65, 5173-5176.

67. Silvi S, Rumney CJ \& Rowland IR (1996) An assessment of three selective media for bifidobacteria in faeces. $J$ Appl Bacteriol 81, 561-564.

68. Rogosa M, Mitchell JA \& Wiseman RF (1951) A selective medium for the isolation and enumeration of oral and fecal lactobacilli. J Bacteriol 62, 132-133.

69. Downes FP \& Ito K (2001) Compendium of Methods for the Microbiological Examination of Foods, 4th ed. pp. 601-648. Washington, DC: American Public Health Association.

70. MacFaddin JD (1985) Media for Isolation-CultivationIdentification-Maintenance of Medical Bacteria. vol. 1, pp. 275-284. Baltimore, MD: Williams \& Wilkins.

71. Amann RI, Ludwig W \& Schleifer KH (1995) Phylogenetic identification and in situ detection of individual cells without cultivation. Microbiol Rev 59, 143-169.

72. Vandamme P, Pot B, Gillis M, et al. (1996) Polyphasic taxonomy, a consensus approach to bacterial systematic. Microbiol Rev 60, 407-438.

73. Woese CR (1987) Bacterial evolution. Microbiol Rev 51, 221-271. 
74. Winker S \& Woese CR (1991) A definition of the domains Archaea, Bacteria and Eucarya in terms of small subunit ribosomal RNA characteristics. Syst Appl Microbiol 14, 305-310

75. DDBJ: DNA Data Bank of Japan (2012) http://www.ddbj. nig.ac.jp/intro-e.html (accessed February 2012).

76. European Bioinformatics Institute (EBI) (2012) Databases at the EBI. http://www.ebi.ac.uk/Databases/

77. National Institutes of Health (NIH) National Center for Biotechnology Information (NCBI) (2012) GenBank. http:// www.ncbi.nlm.nih.gov

78. Muyzer G \& Smalla K (1998) Application of denaturing gradient gel electrophoresis (DGGE) and temperature gradient gel electrophoresis (TGGE) in microbial ecology. Antonie Van Leeuwenhoek 73, 127-141.

79. Langendijk PS, Schut F, Jansen GJ, et al. (1995) Quantitative fluorescence in situ hybridization of Bifidobacterium spp. With genus-specific $16 \mathrm{~S}$ rRNA targeted probes and its application in fecal samples. Appl Environ Microbiol 61, 3069-3075.

80. Fallani M, Young D, Scott J, et al. (2010) Intestinal microbiota of 6-week-old infants across Europe: geographic influence beyond delivery mode, breast-feeding, and antibiotics. I Pediatr Gastroenterol Nutr 51, 77-84.

81. Leblond-Bourget N, Philippe H, Mangin I, et al. (1996) $16 \mathrm{~S}$ rRNA and $16 \mathrm{~S}$ to $23 \mathrm{~S}$ internal transcribed spacer sequence analyses reveal inter-and intraspecific Bifidobacterium phylogeny. Int J Syst Bacteriol 46, 102-111.

82. Fehér T, Burland V \& Pósfai G (2012) In the fast lane: largescale bacterial genome engineering. J Biotechnol 160, $72-79$.

83. de los Reyes-Gavilán CG, Suárez A, Fernández-García M, et al. (2011) Adhesion of bile-adapted Bifidobacterium strains to the HT29-MTX cell line is modified after sequential gastrointestinal challenge simulated in vitro using human gastric and duodenal juices. Res Microbiol 162, 514-519.

84. Masco L, Crockaert C, van Hoorde K, et al. (2007) In vitro assessment of the gastrointestinal transit tolerance of taxonomic reference strains from human origin and probiotic product isolated of Bifidobacterium. J Dairy Sci $\mathbf{9 0}$, $3572-3578$

85. FAO/WHO (2002) Guidelines for the evaluation of probiotics in food. Food and Health Agricultural Organisation of the United Nations - World Health Organisation. Working group report. London, Ontario. http://www.fao.org

86. Sanz Y (2006) Ecological and functional implications of the acid adaptation ability of Bifidobacterium: a way of selecting improved probiotic strains. Int dairy J 17, 1284-1289.

87. Mainville I, Arcand Y \& Farnworth ER (2005) A dynamic model that simulates the human upper gastrointestinal tract for the study of probiotics. Int J Food Microbiol 99, 287-296.

88. Dunne C, O'Mahony L, Murphy L, et al. (2001) In vitro selection criteria for probiotic bacteria of human origin: correlation with in vivo findings. Am J Clin Nutr 73, 386-392.

89. Zavaglia AG, Kociubinsky G, Pérez P, et al. (1998) Isolation and characterization of Bifidobacterium strains for probiotic formulation. J Food Prot 61, 865-873.

90. Charteris WP, Kelly PM, Morelli L, et al. (1998) Development and application of an in vitro methodology to determine the transit tolerance of potentially probiotic Lactobacillus and Bifidobacterium species in the upper human gastrointestinal tract. J Appl Microbiol 84, 759-768.

91. Takahashi N, Xiao JZ, Miyaji K, et al. (2004) Selection of acid tolerant bifidobacteria and evidence for a
low-pH-inducible acid tolerance response in Bifidobacterium longum. J Dairy Res 71, 340-345.

92. Matsumoto M, Ohishi H \& Benno Y (2004) H + -ATPase activity in Bifidobacterium with special reference to acid tolerance. Int J Food Microbiol 93, 109-113.

93. Matto J, Alakomi HL, Vaari A, et al. (2006) Influence of processing conditions on Bifidobacterium animalis subsp., lactis functionality with a special focus on acid tolerance and factors affecting it. Int Dairy J 16, 1029-1037.

94. Chenoll E, Casinos B, Bataller E, et al. (2011) Novel probiotic Bifidobacterium bifidum CECT 7366 strain active against the pathogenic bacterium Helicobacter pylori. Appl Environ Microbiol 77, 1335-1343.

95. Muñoz JA, Chenoll E, Casinos B, et al. (2011) Novel probiotic Bifidobacterium longum subsp. infantis CECT 7210 strain active against rotavirus infections. Appl Environ Microbiol 77, 8775-8783.

96. Li Q, Chen Q, Ruan H, et al. (2010) Isolation and characterisation of an oxygen, acid and bile resistant Bifidobacterium animalis subsp. lactis Qq08. J Sci Food Agric 90, 1340-1346.

97. Bosch M, Rodriguez M, Garcia F, et al. (2012) Probiotic properties of Lactobacillus plantarum CECT 7315 and CECT 7316 isolated from faeces of healthy children. Lett Appl Microbiol 54, 240-246.

98. Mills S, Stanton C, Fitzgerald GF, et al. (2011) Enhancing the stress responses of probiotics for a lifestyle from gut to product and back again. Microb Cell Fact 10, Suppl. 1, S19.

99. Marles-Wright J \& Lewis R (2007) Stress response of bacteria. Curr Opin Struct Biol 17, 755-760.

100. Rizzello CG, Cassone A, Di Cagno R, et al. (2008) Synthesis of angiotensin I-converting enzyme (ACE)-inhibitory peptides and g-aminobutyric acid (GABA) during sourdough fermentation by selected lactic acid bacteria. J Agric Food Chem 56, 6936-6943.

101. Dicks LM \& Botes M (2010) Probiotic lactic acid bacteria in the gastro-intestinal tract: health benefits, safety and mode of action. Benef Microbes 1, 11-29.

102. Lenaerts K, Bouwman FG, Lamers WH, et al. (2007) Comparative proteomic analysis of cell lines and scrapings of the human intestinal epithelium. BMC Genomics 8, 91.

103. Huang SH, He L, Zhou Y, et al. (2009) Lactobacillus rhamnosus GG suppresses meningitic E. coli K1 penetration across human intestinal epithelial cells in vitro and protects neonatal rats against experimental hematogenous meningitis. Int J Microbiol 2009, 647862.

104. Gopal PK, Prasad J, Smart J, et al. (2001) In vitro adherence properties of Lactobacillus rhamnosus DR20 and Bifidobacterium lactis DR10 strains and their antagonistic activity against an enterotoxigenic Escherichia coli. Int $J$ Food Microbiol 67, 207-216.

105. Izquierdo E, Medina M, Ennahar S, et al. (2008) Resistance to simulated gastrointestinal conditions and adhesion to mucus as probiotic criteria for Bifidobacterium longum strains. Curr Microbiol 56, 613-618.

106. Tuomola EM, Ouwehand AC \& Salminen SJ (1999) The effect of probiotic bacteria on the adhesion of pathogens to human intestinal mucus. FEMS Immunol Med Microbiol 26, 137-142.

107. Lesuffleur T, Barbat A, Dussaulx E, et al. (1990) Growth adaption to methotrexate of HT-29 human colon carcinoma cell is associated with their ability to differentiate into columnar absorptive and mucus secreting cells. Cancer Res 50, 6334-6343.

108. Leteurtre E, Gouyer V, Rousseau K, et al. (2004) Differential mucin expression in colon carcinoma HT-29 clones with 
variable resistance to 5-fluorouracil and methotrexate. Biol Cell 96, 145-151.

109. Laparra JM \& Sanz Y (2009) Comparison of in vitro models to study bacterial adhesion to the intestinal epithelium. Lett Appl Microbiol 49, 695-701.

110. Collado MC, Meriluoto J \& Salminen S (2007) Role of commercial probiotic strains against human pathogen adhesion to intestinal mucus. Lett Appl Microbiol 45, 454-460.

111. Salminen S, Bouley C, Boutron-Ruault MC, et al. (1998) Functional food science and gastrointestinal physiology and function. BrJ Nutr 80, 147-171.

112. Sambuy Y, De Angelis I, Ranaldi G, et al. (2005) The Caco-2 cell line as a model of the intestinal barrier: influence of cell and culture-related factors on Caco-2 cell functional characteristics. Cell Biol Toxicol 21, 1-26.

113. Ferreira CL, Grześkowiak $\ell$, Collado MC, et al. (2011) In vitro evaluation of Lactobacillus gasseri strains of infant origin on adhesion and aggregation of specific pathogens. J Food Prot 74, 1482-1487.

114. Todoriki K, Mukai T, Sato S, et al. (2001) Inhibition of adhesion of food-borne pathogens o Caco-2 cells by Lactobacillus strains. J Appl Microbiol 91, 154-159.

115. Chu H, Kang S, Ha S, et al. (2005) Lactobacillus acidophilus expressing recombinant K99 adhesive fimbriae has an inhibitory effect on adhesion of enterotoxigenic Escherichia coli. Microbiol Immunol 49, 941-948.

116. Tsai CC, Lin PP \& Hsieh YM (2008) Three Lactobacillus strains from healthy infant stool inhibit enterotoxigenic Escherichia coli grown in vitro. Anaerobe 14, 61-67.

117. Candela M, Perna F, Carnevali P, et al. (2008) Interaction of probiotic Lactobacillus and Bifidobacterium strains with human intestinal epithelial cells: adhesion properties, competition against enteropathogens and modulation of IL-8 production. Int J Food Microbiol 31, 286-292.

118. Jankowska A, Laubitz D, Antushevich H, et al. (2008) Competition of Lactobacillus paracasei with Salmonella enterica for adhesion to Caco-2 cells. J Biomed Biotechnol 2008, 357964.

119. Tien MT, Girardin SE, Regnault B, et al. (2006) Anti-inflammatory effect of Lactobacillus casei on Shigella-infected human intestinal epithelial cells. $J$ Immunol 176, $1228-1237$.

120. Cho IL, Lee NK \& Hahm YT (2009) Characterization of Lactobacillus spp. isolated from the feces of breast-feeding piglets. J Biosci Bioeng 108, 194-198.

121. Pillai A \& Nelson R (2008) Probiotics for treatment of Clostridium difficile-associated colitis in adults. The Cochrane Database of Systematic Reviews issue 1, CD004611.

122. Wang H, Yan Y, Wang J, et al. (2012) Production and characterization of antifungal compounds produced by Lactobacillus plantarum IMAU10014. PLoS One 7, e29452.

123. Naidoo K, Gordon M, Fagbemi AO, et al. (2011) Probiotics for maintenance of remission in ulcerative colitis. The Cochrane Database of Systematic Reviews issue 12, CD007443.

124. Von Wright A (2005) Regulating the safety of probiotics the European approach. Curr Pharm Des 11, 17-23.

125. Wassenaar TM \& Klein G (2008) Safety aspects and implications of regulation of probiotic bacteria in food and food supplements. J Food Prot 71, 1734-1741.

126. Introduction of a Qualified Presumption of Safety (QPS) approach for assessment of selected microorganisms referred to EFSA (2007). http://www.efsa.europa.eu/en/ efsajournal/pub/587.htm

127. Opinion of the Scientific Committee on Animal Nutrition on the criteria for assessing the safety of micro-organisms resistant to antibiotics of human clinical and veterinary importance (2002). http://ec.europa.eu/food/fs/sc/scan/ out64_en.pdf (accessed February 2012).

128. Sanders ME, Akkermans LM, Haller D, et al. (2010) Safety assessment of probiotics for human use. Gut Microbes 1, $164-185$.

129. Cencič A \& Langerholc T (2010) Functional cell models of the gut and their applications in food microbiology. Int J Food Microbiol 141, Suppl. 1, S4-S14.

130. Borchers AT, Selmi C, Meyers FJ, et al. (2009) Probiotics and immunity. J Gastroenterol 44, 26-46.

131. Asemi Z, Jazayeri S, Najafi M, et al. (2011) Effects of daily consumption of probiotic yoghurt on inflammatory factors in pregnant women: a randomized controlled trial. Pak J Biol Sci 14, 476-482.

132. Asemi Z, Jazayeri S, Najafi M, et al. (2012) Effect of daily consumption of probiotic yoghurt on oxidative stress in pregnant women: a randomized controlled clinical trial. Ann Nutr Metab 60, 62-68.

133. Dugoua JJ, Machado M, Zhu X, et al. (2009) Safety in pregnancy: a systematic review and meta-analysis of RCT of Lactobacillus, Bifidobacterium, and Saccharomyces spp. J Obstet Gynaecol Can 31, 542-552.

134. Vliagoftis H, Kouranos VD, Betsi GI, et al. (2008) Probiotics for the treatment of allergic rhinitis and asthma: systematic review of RCT. Ann Allergy Asthma Immunol 101, $570-579$.

135. Kuitunen M, Kukkonen K \& Savilahti EJ (2009) Pro- and prebiotic supplementation induces a transient reduction in hemoglobin concentration in infants. J Pediatr Gastroenterol Nutr 49, 626-630.

136. Martínez-Cañavate A, Sierra S, Lara-Villoslada F, et al. (2009) A probiotic dairy product containing L. gasseri CECT5714 and L. coryniformis CECT5711 induces immunological changes in children suffering from allergy. Pediatr Allergy Immunol 20, 592-600.

137. Olivares M, Díaz-Ropero MO, Gómez N, et al. (2006) Oral administration of two probiotic strains, Lactobacillus gasseri CECT5714 and Lactobacillus coryniformis CECT5711, enhances the intestinal function of healthy adults. Int $J$ Food Microbiol 107, 104-111.

138. Boyle RJ, Bath-Hextall FJ, Leonardi-Bee J, et al. (2009) Probiotics for treating eczema. A systematic review. Clin Exp Allergy 39, 1117-1127.

139. Lee J, Seto D \& Bielory L (2008) Meta-analysis of clinical trials of probiotics for prevention and treatment of pediatric atopic dermatitis. J Allergy Clin Immunol 121, 116-121.

140. Allen SJ, Martinez EG, Gregorio GV, et al. (2010) Probiotics for treating acute infectious diarrhoea. The Cochrane Database of Systematic Reviews issue 11, CD003048.

141. Johnston BC, Goldenberg JZ, Vandvik PO, et al. (2011) Probiotics for the prevention of pediatric antibiotic-associated diarrhea. The Cochrane Database of Systematic Reviews issue 11, CD004827.

142. Bernaola Aponte G, Bada Mancilla CA, Carreazo Pariasca NY, et al. (2010) Probiotics for treating persistent diarrhoea in children. The Cochrane Database of Systematic Reviews issue 11, CD007401.

143. Alfaleh K, Anabrees J, Bassler D, et al. (2011) Probiotics for prevention of necrotizing enterocolitis in preterm infants. The Cochrane Database of Systematic Reviews issue 3, CD005496.

144. Braga TD, da Silva GAP, de Lira PIC, et al. (2011) Efficacy of Bifidobacterium breve and Lactobacillus casei oral supplementation on necrotizing enterocolitis in 
very-low-birth-weight preterm infants: a double-blind, randomized, controlled trial. Am J Clin Nutr 93, 81-86.

145. Sang LX, Chang B, Zhang WL, et al. (2010) Remission induction and maintenance effect of probiotics on ulcerative colitis: a meta-analysis. World J Gastroenterol 16, $1908-1915$.

146. Mimura T, Rizzello F, Helwig U, et al. (2004) Once daily high dose probiotic therapy (VSL\#3) for maintaining remission in recurrent or refractory pouchitis. Gut 53, 108-114.

147. Kühbacher T, Ott SJ, Helwig U, et al. (2006) Bacterial and fungal microbiota in relation to probiotic therapy (VSL\#3) in pouchitis. Gut 55, 833-841.

148. Doherty GA, Bennett GC, Cheifetz AS, et al. (2010) Metaanalysis: targeting the intestinal microbiota in prophylaxis for post-operative Crohn's disease. Aliment Pharmacol Ther 31, 802-809.

149. McFarland LV \& Dublin S (2008) Meta-analysis of probiotics for the treatment of irritable bowel syndrome. World J Gastroenterol 14, 2650-2661.

150. Gawrońska A, Dziechciarz P, Horvath A, et al. (2007) A randomized double-blind placebo-controlled trial of Lactobacillus GG for abdominal pain disorders in children. Aliment Pharmacol Ther 25, 177-1784.

151. Bausserman M \& Michail S (2005) The use of Lactobacillus GG in irritable bowel syndrome in children: a double-blind randomized control trial. J Pediatr 147, 197-201.

152. Enck P, Zimmermann K, Menke G, et al. (2008) A mixture of Escherichia coli (DSM 17252) and Enterococcus faecalis (DSM 16440) for treatment of the irritable bowel syndrome - a randomized controlled trial with primary care physicians. Neurogastroenterol Motil 20, 1103-1109.

153. Liu JE, Zhang Y, Zhang J, et al. (2010) Probiotic yoghurt effects on intestinal flora of patients with chronic liver disease. Nurs Res 59, 426-432.

154. Aller R, De Luis DA, Izaola O, et al. (2011) Effect of a probiotic on liver aminotransferases in nonalcoholic fatty liver disease patients: a double blind randomized clinical trial. Eur Rev Med Pharmacol Sci 15, 1090-1095.
155. Zhang MM, Cheng JQ, Lu YR, et al. (2010) Use of pre-, proand synbiotics in patients with acute pancreatitis: a metaanalysis. World J Gastroenterol 16, 3970-3978.

156. Sharma B, Srivastava S, Singh N, et al. (2011) Role of probiotics on gut permeability and endotoxemia in patients with acute pancreatitis. J Clin Gastroenterol 45, 442-448.

157. Ejtahed HS, Mohtadi-Nia J, Homayouni-Rad A, et al. (2011) Effect of probiotic yoghurt containing Lactobacillus acidophilus and Bifidobacterium lactis on lipid profile in individuals with type 2 diabetes mellitus. J Dairy Sci 94, 3288-3294.

158. Hummelen R, Changalucha J, Butamanya NL, et al. (2011) Effect of 25 weeks probiotic supplementation on immune function of HIV patients. Gut Microbes 2, 80-85.

159. Trois L, Cardoso EM \& Miura E (2008) Use of probiotics in HIV-infected children: a randomized double-blind controlled study. J Trop Pediatr 54, 19-24.

160. Anukam KC, Osazuwa EO, Osadolor HB, et al. (2008) Yoghurt containing probiotic Lactobacillus rhamnosus GR-1 and $L$. reuteri $\mathrm{RC}-14$ helps resolve moderate diarrhea and increases CD 4 count in HIV/AIDS patients. J Clin Gastroenterol 42, 239-243.

161. Stapleton AE, Au-Yeung M, Hooton TM, et al. (2011) Randomized, placebo-controlled phase 2 trial of a Lactobacillus crispatus probiotic given intravaginally for prevention of recurrent urinary tract infection. Clin Infect Dis 52, $1212-1217$.

162. Hao Q, Lu Z, Dong BR, et al. (2011) Probiotics for preventing acute upper respiratory tract infections. The Cochrane Database of Systematic Reviews issue 9, CD006895.

163. Siempos Nt II, aidou TK \& Falagas ME (2010) Impact of the administration of probiotics on the incidence of ventilatorassociated pneumonia: a meta-analysis of RCT. Crit Care Med 38, 954-962.

164. Jenks K, Stebbings S, Burton J, et al. (2010) Probiotic therapy for the treatment of spondyloarthritis: a randomized controlled trial. J Rbeumatol 37, 2118-2125. 